\title{
Knowledge, attitudes, and practices of primary health care physicians, junior doctors, and medical college students towards autism in Duhok, Iraq
}

Accepted: 18/ 5/ 2020

\begin{tabular}{|c|c|}
\hline & \\
\hline \multicolumn{2}{|c|}{ Abstract } \\
\hline \multicolumn{2}{|c|}{$\begin{array}{l}\text { Background and objective: The knowledge of autism spectrum disorder among } \\
\text { physicians and medical students is limited. This study aimed to find out the level of } \\
\text { knowledge, attitudes, and practices of primary health care physicians, junior doctors, and } \\
6^{\text {th }} \text { year medical college students in Duhok province, Iraqi Kurdistan toward autism } \\
\text { spectrum disorder. } \\
\text { Methods: A cross-sectional study was carried out from September } 10^{\text {th }} \text { until October } 30^{\text {th }} \text {, } \\
2016 \text {. A self-administered questionnaire was used for data collection. Two hundred and } \\
\text { two questionnaires were completed by the three participants' groups. Data analysis was } \\
\text { carried out using the statistical analysis system (SAS, version } 9.4) \text {. } \\
\text { Results: Of the } 202 \text { participants, } 24.8 \% \text { were sixth year medical students, others were } \\
\text { junior doctors ( } 35.6 \%) \text { and primary health care physicians }(39.6 \%) \text {. Of them, } 51.5 \% \text { were } \\
\text { females and } 48.5 \% \text { were males. High percentages }(90.1 \% \text { and } 91.1 \%) \text { of respondents } \\
\text { heard and knew about autism spectrum disorder, respectively. They showed poor } \\
\text { information on identification and management. Primary health care physicians had more } \\
\text { knowledge on the genetic basis of autism ( } P<0.001) \text { and behavioral therapy for autism } \\
(P=0.016) \text {. No significant differences in knowledge was found between both gender } \\
\text { groups except that female participants had limited knowledge on its genetic basis } \\
(P=0.007) \text {. } \\
\text { Conclusion: Although primary health care physicians, rotators, and medical students } \\
\text { generally heard about autism spectrum disorder, they had limited knowledge of its } \\
\text { diagnosis and management. It is recommended to introduce autistic disorders lectures to } \\
\text { the medical college curriculum and training of physicians by experienced professionals. } \\
\text { Keywords: KAP; Physicians; Medical students; Autism. }\end{array}$} \\
\hline \multicolumn{2}{|l|}{ Introduction } \\
\hline $\begin{array}{l}\text { The general knowledge of mental health } \\
\text { among general practitioners and primary } \\
\text { health care (PHC) physicians is limited, as } \\
\text { identified by more than } 400 \text { articles. }{ }^{1} \text { This } \\
\text { gap in knowledge on mental illnesses could } \\
\text { be filled with continuous medical education } \\
\text { (CME). }{ }^{2} \text { In Arabian Gulf countries, including } \\
\text { Iraq and Iraqi Kurdistan, primary care } \\
\text { physicians are somewhat less efficacious } \\
\text { in dealing with patients having psychiatric } \\
\text { disorders. }{ }^{3} \text { One of the important challenges } \\
\text { of child mental health nowadays is autistic } \\
\text { disorders. Autism spectrum disorders } \\
\text { (ASD) are disseminated, and lifelong }\end{array}$ & 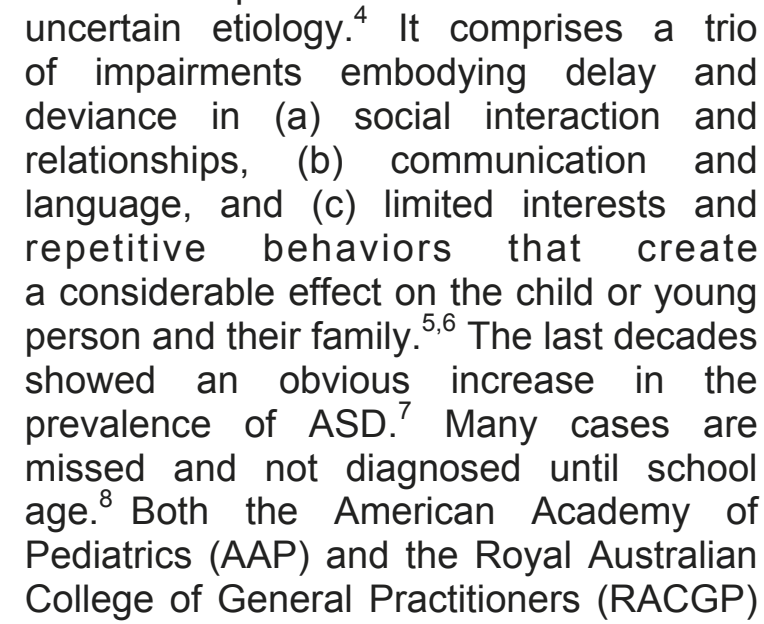 \\
\hline
\end{tabular}


insisted on the important role of primary care providers in the early detection of autism. ${ }^{9,10}$ The process of referring to specialist services is enhanced and strengthened by the perfect process of early detection of ASD, which consequently resulted in early intervention. ${ }^{11,12}$ A survey in the United States of America showed differences in knowledge of autism between PHC providers and specialists like psychologists, psychiatrists, and speech therapists. ${ }^{13}$ On another side of the world, misunderstandings about the etiology, treatment, and prognosis of ASD were found among health care workers in Sub-Saharan African subcultures. ${ }^{14}$ In developing countries, the health staff concentrates more on tropical diseases with shortages in their knowledge concerned the developmental milestones field. ${ }^{15,16}$ Intrinsically, the documented deficit of knowledge about ASD in between health care workers may be due to a flaw in the academic education system with the inadequacy of practical training and insufficient theoretical lectures provided in terms of pediatrics, psychiatry, and psychology. ${ }^{17,18}$ For this reason, the level of knowledge on ASD among final year undergraduate medical, nursing, and psychology students should be well assessed. They will be future members of the multidisciplinary team responsible for taking care of autistic children. ${ }^{19-21}$
The current study was performed to investigate the knowledge, attitude, and practice (KAP) toward ASD among $\mathrm{PHC}$ physicians, junior doctors, and $6^{\text {th }}$ year medical college students in Duhok province, Iraqi Kurdistan.

\section{Methods}

\section{Study setting and design}

A cross sectional study was carried out to assess the KAP of current physicians (PHC physicians and junior doctors) working at the Directorate of Health, Duhok and $6^{\text {th }}$ year medical college students from the University of Duhok. The participants responded to a questionnaire designed to assess KAP toward ASD. Four interviewers entered a training course of two days to practice the questionnaire in the psychiatric department in Azadi teaching hospital. During about two months, they conducted their interviews with participants from Duhok city and surrounding areas.

\section{Participants}

The General Directorate of Health in Duhok governorate had seven health sectors, including Duhok Center sector. Meantime, there were 50 students in the $6^{\text {th }}$ year of the medical college at the University of Duhok during the academic year 2015-2016, and all were invited to participate in our study. The study population was 202, according to Table 1 .

Table 1: Distribution of the sample according to the workplace.

\begin{tabular}{lc}
\hline Sector & Participants \\
\hline Students of medical college $\left(\mathbf{6}^{\text {th }}\right.$ year) & $\mathbf{5 0}$ \\
Physicians: PHC physicians and junior doctors & $\mathbf{1 5 2}$ \\
Physicians in Duhok city & 79 \\
Physicians in Zakho city & 19 \\
Physicians in Summel town & 14 \\
Physicians in Amediye town & 18 \\
Physicians in Shekhan town & 8 \\
Physicians in Bardarash town & 5 \\
Physicians in Akre city & 9 \\
Total & $\mathbf{2 0 2}$ \\
\hline
\end{tabular}




\section{Study Instruments}

A questionnaire was designed by the authors to assess KAP toward ASD among participants who are physicians and medical college students. The instrument was designed in such a way as to cover all aspects of KAP. The first part included some demographic data of the participant like gender, age, place of work, number of years of experience. The second part of the study tool composed of 20 questions covering areas of KAP toward ASD including the three main domains of clinical information and etiology, diagnosis, and treatment of ASD. The validity of the research tool was done by presenting the instrument to four specialists, including two psychiatrists and two community medicine specialists, to review it and give their valuable notes, which were applied to the original questionnaire.

\section{The Pilot Study}

Then a pilot study that lasted for seven days was conducted after discussions with experts. It has been conducted through using a small group of respondents consists of $10 \mathrm{PHC}$ physicians, five junior doctors, and five medical college students of $6^{\text {th }}$ year, those who were not included in the study. The investigators did their pilot study to train on the questionnaire, achieve more practice, and estimate the appropriate time required to complete the survey.

\section{Data Analysis}

Data from 152 physicians and 50 medical students were extracted from the survey instrument/responses and entered into Microsoft Excel. The data were then cleaned and formatted for input into statistical software. Data were imported into the statistical analysis system (SAS) software and analyzed. Descriptive statistics were used to summarize physician responses as presented in the results section. The distribution of physician and medical student's correct responses were determined and presented. Chi-square tests were conducted to check for any significant difference among the physician types and student responses. A $P \leq 0.05$ was considered statistically significant, and a $P<0.001$ was considered highly significant. Likewise, Chi-square tests were performed to check for any significant differences by gender. Percentages for the correct answer of knowledge, identification, and management of autism were identified. Chi-square test was performed to check for any significant differences among the physician groups with regard to the percentages of correct answers. Data were analyzed using SAS version 9.4 (SAS Institute, Cary, NC).

\section{Ethical Consideration}

This study was approved by the ethics committee of the College of Medicine, University of Dohuk. Informed written consent was obtained from all participants, and an information leaflet has been provided at the time of implementing the study.

\section{Results}

The total number of participants in this survey was $202 ; 51.5 \%$ were females, and $48.5 \%$ were males. Most of the respondents were between the age of 25 and 34 years $(68.8 \%)$. Fifty of them were $6^{\text {th }}$ year medical students $(24.8 \%)$, the 72 junior doctors were $35.6 \%$, and the PHC physicians were 80 making $39.6 \%$. About $75.3 \%$ of the physicians had $1-5$ years of experience. Nearly half of the participants have taken a training course on ASD, $45.1 \%$ included in the college curriculum and $11.9 \%$ outside the college, as shown in Table 2. 
Table 2: Demographic characteristics of the study sample

\section{Characteristic}

$\mathrm{N}=202(\%)$

\section{Sex}

Female

$104(51.5)$

Male

$98(48.5)$

Age (years)

$18-24$

$50(24.8)$

$25-34$

139(68.8)

$\geq 35$

Position

$6^{\text {th }}$ year student

$50(24.8)$

Junior/Rotator

$72(35.6)$

PHC physician

$80(39.6)$

Years of service for physicians $(n=150)$

$<1$

18(12.0)

1 to 5

113(75.3)

6 to 10

11 to 20

$\geq 21$

Training $(n=202)$

Have taken a course on ASD

Other training outside of college on ASD

$24(11.9)$ 
Table 3 shows the number and of autism by physicians' types and $6^{\text {th }}$ year percentages of correct responses about medical students, separately and totally. knowledge, identification, and management

Table 3: Distribution of physicians' and medical students' correct responses.

\begin{tabular}{|c|c|c|c|c|c|}
\hline Area of KAP & $\begin{array}{l}\text { Medical } \\
\text { student } \\
(n=50)\end{array}$ & $\begin{array}{l}\text { Junior I } \\
\text { Rotator } \\
(\mathrm{n}=72)\end{array}$ & $\begin{array}{l}\text { PHC- } \\
\text { Doctor } \\
(n=80)\end{array}$ & $P$ value & $\begin{array}{c}\text { Total } \\
\text { number (\%) } \\
(\mathrm{n}=202)\end{array}$ \\
\hline \multicolumn{6}{|l|}{ Knowledge } \\
\hline Heard about ASD & $41(82.0)$ & $66(91.7)$ & $75(93.8)$ & 0.079 & $182(90.1)$ \\
\hline Knows what $A S D$ is & $43(86.0)$ & $67(93.1)$ & $74(92.5)$ & 0.344 & $184(91.1)$ \\
\hline Definition of ASD & $15(30.0)$ & $23(31.9)$ & $36(45.0)$ & 0.133 & $74(36.6)$ \\
\hline Age ASD diagnosed & $36(72.0)$ & $63(87.5)$ & $62(77.5)$ & 0.092 & $161(79.7)$ \\
\hline $\begin{array}{l}\text { Gender rates of occurrence } \\
\text { of ASD }\end{array}$ & $29(58.0)$ & $38(52.8)$ & $52(65.0)$ & 0.307 & $119(58.9)$ \\
\hline ASD and genetic basis & $21(42.0)$ & $12(16.7)$ & $37(46.3)$ & $<0.001$ & $70(34.7)$ \\
\hline $\begin{array}{l}\text { Pollution as being an } \\
\text { environmental factor }\end{array}$ & $23(46.0)$ & $21(29.2)$ & $36(45.0)$ & 0.078 & $80(39.6)$ \\
\hline $\begin{array}{l}\text { Relationship between ASD and } \\
\text { diet }\end{array}$ & $4(8.0)$ & $9(12.5)$ & $15(18.8)$ & 0.207 & $28(13.9)$ \\
\hline ASD being curable condition & $22(44.0)$ & $25(34.7)$ & $32(40.0)$ & 0.574 & $79(39.1)$ \\
\hline \multicolumn{6}{|l|}{ Identification } \\
\hline Diagnosis of ASD dependence & $27(54.0)$ & $39(54.2)$ & $47(58.8)$ & 0.809 & $113(55.9)$ \\
\hline $\begin{array}{l}\text { Requirement of laboratory to } \\
\text { diagnose ASD }\end{array}$ & $12(24.0)$ & $22(30.6)$ & $22(27.5)$ & 0.728 & $56(27.7)$ \\
\hline $\begin{array}{l}\text { Existence of proper facilities for } \\
\text { labs regarding ASD }\end{array}$ & $33(66.0)$ & $41(56.9)$ & $48(60.0)$ & 0.600 & $122(60.4)$ \\
\hline $\begin{array}{l}\text { Heard of Childhood Autism Rating } \\
\text { Scale }\end{array}$ & $7(14.0)$ & $13(18.1)$ & $18(22.5)$ & 0.47 & $38(18.8)$ \\
\hline $\begin{array}{l}\text { Childhood Autism Rating Scale } \\
\text { usage }\end{array}$ & $1(2.0)$ & $3(4.2)$ & $3(3.8)$ & 0.800 & $7(3.5)$ \\
\hline \multicolumn{6}{|l|}{ Management } \\
\hline $\begin{array}{l}\text { Behavioral therapy is best } \\
\text { management option }\end{array}$ & $42(84.0)$ & $55(76.4)$ & 67 (83.8) & 0.430 & $164(81.2)$ \\
\hline $\begin{array}{l}\text { Scientifically-practical-concerned } \\
\text { programs and Behavioral Therapy }\end{array}$ & $3(6.0)$ & $14(19.4)$ & $21(26.3)$ & 0.016 & $38(18.8)$ \\
\hline $\begin{array}{l}\text { Final treatment decision after } \\
\text { diagnosis }\end{array}$ & $11(22.0)$ & $14(19.4)$ & $14(17.5)$ & 0.818 & $39(19.3)$ \\
\hline $\begin{array}{l}\text { Referral to Specific Center for } \\
\text { Autism }\end{array}$ & $15(30.0)$ & $7(9.7)$ & $12(15.0)$ & 0.011 & $34(16.8)$ \\
\hline
\end{tabular}


Speaking about the results of all participants together, $90 \%$ of them responded positively about the first two questions of the questionnaire, which are mostly subjective on knowledge of autism. Regarding the third question, which wonders autism to be defined as which type of disorders, only $36.6 \%$ of respondents gave the correct answer as a neurodevelopmental disorder among four alternative answers. The age at which autism can be diagnosed and the gender differences in the occurrence of this disorder were also answered correctly by $79.7 \%$ and $58.9 \%$ of participants. Questions 6-8 of this instrument were concerning knowledge of etiology and were mostly wrongly answered by participants. Genetic factors, environmental and diet relationship to etiology of autistic disorder were answered correctly only by $34.7 \%, 39.6 \%$, and $13.9 \%$ of respondents. Question 9 of knowledge is whether autism is a curable disorder and again was answered correctly by only $39.1 \%$. Regarding the second part of the questionnaire, which is specific for the identification of autism, five questions are included. The first question, which is concerned with the best way of confirmation of autism diagnosis, is answered correctly by nearly half of the participants $(55.9 \%)$. The remaining four questions deliver Yes, or No answers are specified for tools of Autism identification and are mostly answered incorrectly. The questions were concerned with laboratory requirements, local laboratory services, autism rating scale, and whether there is previous or current usage by the participant. The responses percentages were: $27.7 \%, 60.4 \%, 18.8 \%$, and $3.5 \%$ respectively. The third part of the instrument deals with the management of autistic disorders and consists of four questions. Behavioral therapy to be the best way of autism management was the content of the first question and was answered correctly by most of the respondents $(81.2 \%)$. The second concern of the management is whether the participant has any idea about an applicable scientifically practical concerned programs, was wrongly answered by most of the respondents i.e., only $18.8 \%$ of them answered it correctly. The last two questions on management were providing multiple choices and were also mostly answered wrongly. The question of final treatment decision and the preferable center of referral of autistic patients were answered correctly by only $19.3 \%$ and $16.8 \%$, respectively. The pattern of distribution of correct responses among the physicians and students is also clarified in Table 3. The three groups had similar responses in most areas of the questionnaire except for three questions: one is concerned with knowledge, and the other two were concerned with management. Regarding the genetic bases as etiology of autism, there was a highly significant difference between the responses of the three groups $(P<0.001)$. $\mathrm{PHC}$ doctors and sixth year medical students had more correct answers percentages than the junior doctors, $46.3 \%$ and $42 \%$, in contrast to $16.7 \%$. Although most of the responses about whether the respondents have an idea about an applicable scientific practical concerned program used in behavioral therapy were negative, the PHC doctors showed more positive answers $(26.3 \%)$ in comparison to $19.4 \%$ and $6 \%$ of the other two groups. Regarding referral to specific centers of autism management and rehabilitation, the question was more correctly answered by $6^{\text {th }}$ year medical students $(30 \%)$ in comparison to $15 \%$ and $9.7 \%$ of other groups. Differences between gender groups are shown in Table 4 . There were no significant differences between the male and female respondents except the question concerning the genetic etiological factors of autism which was answered correctly by males $43.9 \%$ vs. only $26 \%$ of females $(P=0.008)$. 
Table 4. Distribution of responses by gender.

\begin{tabular}{|c|c|c|c|}
\hline & \multicolumn{2}{|c|}{ Gender $(N=202)$} & \multirow[b]{2}{*}{$P$ value } \\
\hline & Female & Male & \\
\hline Knowledge & $N=104$ & $N=98$ & \\
\hline 1. Heard about ASD & $95(91.4)$ & $87(88.8)$ & 0.541 \\
\hline 2. Knows what $A S D$ is & $95(91.4)$ & $89(90.8)$ & 0.895 \\
\hline 3. Definition of ASD & $43(41.4)$ & $31(31.6)$ & 0.152 \\
\hline 4. Age ASD diagnosed & $82(78.9)$ & $79(80.6)$ & 0.755 \\
\hline 5. Gender rates of ASD & $66(63.5)$ & $53(54.1)$ & 0.176 \\
\hline 6. ASD and genetic basis & $27(26.0)$ & $43(43.9)$ & 0.008 \\
\hline 7. Pollution as being an environmental factor & $45(43.3)$ & $35(35.7)$ & 0.273 \\
\hline 8. Relationship between ASD and diet & $19(18.3)$ & $9(9.2)$ & 0.062 \\
\hline 9. ASD being curable condition & $41(39.4)$ & $38(38.8)$ & 0.925 \\
\hline \multicolumn{4}{|l|}{ Identification } \\
\hline 1. Diagnosis of ASD dependence & $55(52.9)$ & $58(59.2)$ & 0.368 \\
\hline 2. Requirement of laboratory to diagnose ASD & $29(27.9)$ & $27(27.6)$ & 0.958 \\
\hline $\begin{array}{l}\text { 3. Existence of proper facilities for labs regarding } \\
\text { ASD }\end{array}$ & $64(61.5)$ & $58(59.2)$ & 0.732 \\
\hline 4. Heard of Childhood Autism Rating Scale & $21(20.2)$ & $17(17.4)$ & 0.605 \\
\hline 5. Childhood Autism Rating Scale usage & $4(3.9)$ & $3(3.1)$ & 0.761 \\
\hline \multicolumn{4}{|l|}{ Management } \\
\hline 1. Behavioral Therapy best management option & $83(79.8)$ & $81(82.7)$ & 0.605 \\
\hline $\begin{array}{l}\text { 2. Scientifically-practical-concerned programs and } \\
\text { Behavioral Therapy }\end{array}$ & $21(20.2)$ & $17(17.4)$ & 0.605 \\
\hline 3. Final treatment decision after diagnosis & $22(21.2)$ & $17(17.4)$ & 0.493 \\
\hline 4. Referral to Specific Center for Autism & $17(16.4)$ & $17(17.4)$ & 0.849 \\
\hline
\end{tabular}




\section{Discussion}

Up to our knowledge, this study can be regarded as the first one in Iraq examining the knowledge, attitude, and practice of graduate doctors, general practitioners, and medical students on autistic disorders. There are suggestions that physicians, in order to make an early diagnosis of ASD and giving the needed support to their parents, must be acknowledgeable on current researches on ASD. ${ }^{22}$ In general, a higher proportion of the respondents heard about and know what autism is. Differences between the three groups are clear regarding knowing and hearing about autism. This may be due to the differences in working experience and years of serving as health workers, which are higher in PHC doctors than junior doctors and, in turn, more than medical students. This can be explained on the basis of their experience. Eseigbe and colleagues' study on knowledge of childhood autism among medical doctors in Kaduna state, northwest Nigeria, displayed similar results in which the doctors presented an appreciable knowledge of autism. ${ }^{23}$ Additionally, the latter study showed that psychiatrists and pediatric doctors have more knowledge than other specialties, which again depend on their past attendance to autistic children. While most of the participants have heard about and know what autism is, still only a lesser percentage of them have appropriate knowledge of the etiology of autism. The findings were similar to other studies like the survey in Nigeria in which $58.2 \%, 14.2 \%$, and $26.9 \%$ of their healthcare workers have information about etiological factors of childhood autism that can be explained by natural, preternatural, and supernatural causes, respectively. ${ }^{24}$ The majority of medical doctors in Siri Lanka $(61.9 \%)$ regarded themselves as incapable of diagnosing autism. ${ }^{25}$ Although most of the respondents in our study knew the age of diagnosis of autism which is at three years, physicians in other countries have different percentages of correct answers. ${ }^{26}$ In Pakistan, only $56.2 \%$ of them recognized that the onset of symptoms of autism should be before 36 months. ${ }^{27}$ Around third of the participants in this study could define autism as a neurodevelopmental disorder. This was lesser than what doctors of Colombo south teaching hospital reported, in which $64.2 \%$ of them regarded autism as a neurodevelopmental disorder. $^{25}$ In Lahore, Pakistan, $51 \%$ of physicians considered autism a developmental disorder. ${ }^{27}$ Less than half of the participants believe that autism is a curable condition. This was close to the opinions of Nigerian health care workers in which $54.5 \%$ and $32.1 \%$ of them subscribed that autism is a treatable and preventable condition, respectively. ${ }^{24}$ The three groups of respondents were not knowledgeable about treatment options, including the concerned treatment programs, treatment decisions, and referral to specified centers. The correct answers were chosen by only $16.8 \%$ and $19.3 \%$ of all participants together. This may be due to the deficiency of services and centers specialized for ASD treatment in our locality. Other studies provided similar findings; only $15-34 \%$ gave advice on medical or educational programs, and $6 \%$ advised referral to ASD specialists. ${ }^{22}$ The exception was the agreement of most respondents of our study on behavioral therapy to be the best treatment options. The gender variation on knowledge about autism was not seen in this study in most areas of assessment. Bakare $\mathrm{MO}$ et al. study showed no significant gender differences in Autism knowledge. ${ }^{16}$ The only significant association with gender was one item related to the etiology of autism. Male doctors and medical students were significantly more likely to recognize the genetic basis of autism. The knowledge gap in this study and other similar studies could view the deficient autism education in the medical academic discipline and in the professional formative practice. Insufficient knowledge in these areas may lead to delay recognition, identification, or 
intervention. This may, in turn, result in leaving them untreated and worsen the quality of life of autistic persons and their parents. Several limitations existed in the present study. The sample size was somewhat small, making it possible that the results are not reflecting the actual knowledge of the medical students and doctors. Limiting the study to only $6^{\text {th }}$ year medical students, rotators, and PHC physicians was the second limitation. Specialist doctors and other health care workers were not included, and they may be less or more knowledgeable about autism. The questionnaire is designed to be self-administered and gathered immediately. It is not covering all etiological factors of autism, the comorbidities of autism like seizure and intellectual disabilities, and does not contain all management routes. Additionally, it cannot assess the cultural beliefs held by the participants about autism.

\section{Conclusion}

The majority of participants knows and heard about ASD, but they showed poor information on its definition, identification, and management. PHC physicians' knowledge of genetic etiological factors of autism and behavioral therapy was better compared to the other two groups. It is recommended to introduce autistic disorders lectures to the medical college curriculum and more medical training for physicians. This may enhance better access to care for autistic children in their early stages and improve parents' care by education.

\section{Competing interests}

The authors declare no competing interests.

\section{References}

1. Hodges B, Inch C, Silver I. Improving the psychiatric knowledge, skills, and attitudes of primary care physicians, 1950-2000: A review. Am J Psychiatry 2001; 158(10):1579-86.

2. Ndetei DM, Khasakhala LI, Mutiso V,
Mbwayo AW. Knowledge, attitude and practice (KAP) of mental illness among staff in general medical facilities in Kenya: practice and policy implications. Afr J Psychiatry 2011; 14(3):22535.

3. Chisholm D, Sekar K, Kumar KK, Saeed K, James S, Mubbashar M, et al. Integration of Mental Health Care into Primary Care. Demonstration cost-outcome study in India and Pakistan. Br J Psychiatry 2000; 176(6):581-8.

4. American Psychiatric Association. Diagnostic and Statistical Manual of Mental Disorders. $5^{\text {th }}$ ed. Arlington, VA: American Psychiatric Association; 2013. P. 50-4.

5. Van-Cong $\mathrm{T}$, Weiss $\mathrm{B}$, Toan KN, Le-Thu TT, Trang NT, Hoa NT, et al. Early identification and intervention services for children with autism in Vietnam. Heal Psychol Rep 2016; 3(3):191-200.

6. Johnson CP, Myers SM. Identification and evaluation of children with autism spectrum disorders. Pediatrics 2007; 120(5):1183-215.

7. Fombonne E, Quirke S, Hagen A. Epidemiology of Pervasive Developmental Disorders. In: Amaral D, Geschwind D, Dawson G, editors. Autism Spectr Disord. Oxford, UK: Oxford University Press; 2011. P. 90-111.

8. Ramaswamy R, Shidhaye R, Nanda S. Making complex interventions work in low resource settings: developing and applying a design focused implementation approach to deliver mental health through primary care in India Background and context. Int J Ment Health Syst 2018; $12: 5$.

9. Manning-courtney $\mathrm{P}$, Murray D, Currans $\mathrm{K}$, Johnson H, Bing N, Kroeger-Geoppinger K, et al. Autism spectrum disorders. Curr Probl Pediatr Adolesc Health Care 2013; 43(1):2-11.

10. Filipek PA, Accardo PJ, Ashwal S, Baranek GT, Cook EH, Dawson G, et al. Practice parameter: Screening and diagnosis of autism Report of the Quality Standards Subcommittee of the American Academy of Neurology and the Child. Neurology 2000; 55(4):468-79.

11. Warren Z, McPheeters ML, Sathe N, Foss-Feig $\mathrm{JH}$, Glasser A, Veenstra-VanderWeele J. Systematic review of early intensive intervention for autism spectrum disorders. Pediatrics 2011; 127(5):e1303-11.

12. Zwaigenbaum L, Bryson S, Lord C, Rogers S, Carter A, Carver L, et al. Clinical assessment and management of toddlers with suspected autism spectrum disorder: Insights from studies of high-risk infants. Pediatrics 2009; 123(5):138391.

13. Heidgerken AD, Geffken G, Modi A, Frakey L. A survey of autism knowledge in a health care setting. J Autism Dev Disord 2005; 35(3):323-30.

14. Igwe MN, Ahanotu AC, Bakare MO, Achor JU, Igwe C. Assessment of knowledge about childhood autism among paediatric and psychiatric nurses in Ebonyi state, Nigeria. 
Child Adolesc Psychiatry Ment Health 2011; 5:1.

15. Lian WB, Ho SK, Yeo CL, Ho LY. General practitioners' knowledge on childhood developmental and behavioural disorders. Singapore Med J 2003; 44(8):397-403.

16. Bakare $\mathrm{MO}$, Ebigbo $\mathrm{PO}$, Agomoh $\mathrm{AO}$, Eaton J, Onyeama GM, Okonkwo KO, et al. Knowledge about childhood autism and opinion among healthcare workers on availability of facilities and law caring for the needs and rights of children with childhood autism and other developmental disorders in Nigeria. BMC Pediatr 2009; 9:12.

17. Bakare MO, Ebigbo PO, Agomoh AO, Menkiti NC. Knowledge about childhood autism among health workers (KCAHW) questionnaire: Description, reliability and internal consistency. Clin Pract Epidemiol Ment Heal 2008; 4(1):17.

18. Zwaanswijk M, Verhaak PF, van der Ende J, Bensing JM, Verhulst FC. Consultation for and identification of child and adolescent psychological problems in Dutch general practice. Fam Pract 2005; 22(5):498-506.

19. Igwe MN,Bakare MO, Agomoh AO, Onyeama $\mathrm{GM}$, OkonkwoKO. Factors influencing knowledge about childhood autism among final year undergraduate Medical , Nursing and Psychology students of University ofNigeria, Enugu State, Nigeria. Ital J Pediatr 2010; 36:44.

20. Khan F, Shehzad R, Chaudhry H. Child and adolescent mental health services in Pakistan: current situation, future directions and possible solutions. Int Psychiatry 2008; 5(4):86-8.

21. Hussein S. A review of global issues and prevalence of child mental health Problems; Where does CAMH stand in Pakistan. J Pakistan Psychiatr Soc 2009; 6(1):5-13.

22. Rhoades RA, Scarpa A, Salley B. The importance of physician knowledge of autism spectrum disorder: Results of a parent survey. BMC Pediatr 2007; 7:37.

23. Eseigbe EE, Nuhu FT, Sheikh TL, Eseigbe $P$, Sanni KA, Olisah VO. Knowledge of childhood autism and challenges of management among medical doctors in Kaduna State, Northwest Nigeria. Autism Res Treat 2015; 892301.

24. Bakare MO, Agomoh AO, Ebigbo PO, Eaton J, Okonkwo KO, Onwukwe JU, et al. Etiological explanation, treatability and preventability of childhood autism: A survey of Nigerian healthcare workers' opinion. Ann Gen Psychiatry 2009; 8:6.

25. Rohanachandra YM, Dahanayake DA, Rohanachandra LT, Wijetunge GS. Knowledge about diagnostic features and comorbidities of childhood autism among doctors in a tertiary care hospital. Sri Lanka J Child Health 2017; 46(1):29_ 32.

26. Goldberg WA, Osann K, Filipek PA, Laulhere T, Jarvis $\mathrm{K}$, Modahl $\mathrm{C}$, et al. Language and other regression: Assessment and timing. J Autism Dev Disord 2003; 33(6):607-16.
27. Imran N, Chaudry MR, Azeem MW, Bhatti MR, Choudhary ZI, Cheema MA. A survey of Autism knowledge and attitudes among the healthcare professionals in Lahore, Pakistan. BMC Pediatr 2011; 11:107. 